in vivo $35: 1177-1183(2021)$

doi:10.21873/invivo.12366

\title{
Crossed Cerebellar Diaschisis in Alzheimer's Disease Detected by Arterial Spin-labelling Perfusion MRI
}

\author{
ALEXANDER HERTEL ${ }^{1}$, HOLGER WENZ ${ }^{1}$, MANSOUR AL-ZGHLOUL ${ }^{1}$, LUCREZIA HAUSNER $^{2}$, \\ LUTZ FRÖLICH $^{2}$, CHRISTOPH GRODEN ${ }^{1}$ and ALEX FÖRSTER ${ }^{1}$ \\ ${ }^{1}$ Department of Neuroradiology, Universitätsmedizin Mannheim, University of Heidelberg, Mannheim, Germany; \\ ${ }^{2}$ Department of Geriatric Psychiatry, Zentralinstitut für Seelische Gesundheit, \\ University of Heidelberg, Mannheim, Germany
}

\begin{abstract}
Background: Crossed cerebellar diaschisis (CCD) is a phenomenon with depressed metabolism and hypoperfusion in the cerebellum. Using arterial spin-labelling perfusion weighted magnetic resonance imaging (ASL PWI), we investigated the frequency of $C C D$ in patients with Alzheimer's disease $(A D)$ and differences between patients with and without CCD. Patients and Methods: In patients with $A D$ who underwent a standardized magnetic resonance imaging including ASL PWI cerebral blood flow was evaluated in the cerebellum, and brain segmentation/ volumetry was performed using mdbrain (mediaire $\mathrm{GmbH}$, Berlin, Germany) and FSL FIRST (Functional Magnetic Resonance Imaging of the Brain Software Library). Results: In total, 65 patients were included, and 22 (33.8\%) patients were assessed as being CCD-positive. Patients with CCD had

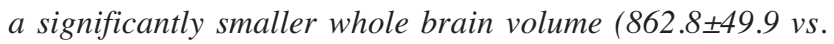
$893.7 \pm 62.7 \mathrm{ml}, p=0.049)$ as well as white matter volume (352.9 \pm 28.0 vs. 374.3 $\pm 30.7, p=0.008)$ in comparison to patients without CCD. Conclusion: It was possible to detect $C C D$ by ASL PWI in approximately one-third of patients with $A D$ and was associated with smaller whole brain and white matter volume.
\end{abstract}

The medical term 'diaschisis' was first established by the Russian neurologist and neuropathologist Constantin von Monakow in 1914 to describe a state of neural depression in the brain caused by loss of connections to injured neural

This article is freely accessible online.

Correspondence to: Alex Förster, MD, Department of Neuroradiology, Universitätsmedizin Mannheim, University of Heidelberg, TheodorKutzer-Ufer 1-3, 68167 Mannheim, Germany. Tel: +49 6213832443, Fax: +49 6213832165, e-mail: Alex.Foerster@umm.de

Key Words: Crossed cerebellar diaschisis, diaschisis, Alzheimer's disease, arterial spin labeling, ASL, perfusion. structures remote from the affected brain area (1). The pathophysiological concept of diaschisis is now widely accepted and many articles concerning different aspects of this phenomenon have been published (2-4). In most of these studies, positron-emission tomography has been used to demonstrate hypometabolism or hypoperfusion in brain areas distant from the actual lesion such as the ipsilateral cerebral cortex $(5,6)$ or the contralateral cerebellum (7-11). The latter phenomenon has also been referred to as crossed cerebellar diaschisis (CCD) and refers to a reduced blood flow and metabolism in the cerebellar hemisphere contralateral to a focal supratentorial lesion. Classically, CCD has been reported in patients with stroke but an association with other forms of brain injury such as supratentorial tumour, epilepsy, radiation necrosis, and encephalitis has also been reported. Besides structural injury, functional impairment and disconnection such as seen during the Wada test (12) or migrainous aura attacks (13) may also result in CCD. Similarly, CCD has been reported occasionally in patients with Alzheimer's disease $(14,15)$. Alzheimer's disease is a neurodegenerative disease which leads to neuronal loss and consequently brain atrophy, especially in the temporal, parietal and frontal lobe (16). Since brain atrophy associated with Alzheimer's disease may develop asymmetrically, it generally provides the pathophysiological basis for the development of CCD (17). Another form of diaschisis, ipsilateral thalamic diaschisis (ITD), was frequently observed in patients with infarction in the vascular territory of the middle cerebral artery (18).

In most studies, positron-emission tomography or single photon-emission computed tomography was used to detect CCD (5-7, 9-12, 14, 15). Nevertheless, it has been demonstrated that magnetic resonance imaging (MRI) perfusion techniques may also be feasible for detecting CCD in supratentorial intracerebral hemorrhage and ischemic infarction $(19,20)$. More recently, several studies have shown that arterial spin labeling perfusion MRI (ASL PWI) is also capable of detecting CCD in patients with ischemic 
stroke (21-23), after brain tumour surgery (24) and epilepsy $(25,26)$. In contrast to dynamic susceptibility contrast perfusion MRI, ASL PWI can be used for quantitative cerebral blood flow $(\mathrm{CBF})$ measurements without the need for injecting exogenous contrast agents using magnetically labelled blood water as an endogenous tracer (27). The ASL perfusion MRI can be performed using continuous or pulsed labelling techniques (28-31).

In the present study, we sought to evaluate (i) whether ASL PWI is feasible for detecting CCD and ITD in patients with Alzheimer's disease, (ii) its frequency in this patient population, as well as (iii) differences between patients with and without CCD or ITD, respectively.

\section{Patients and Methods}

Patients. From a prospectively maintained MRI report we identified 76 patients with diagnosis of dementia, which was probably caused by Alzheimer's disease [National Institute of Neurological Disorders and Stroke Alzheimer's Disease and Related Disorders Association Alzheimer's Criteria after McKhann et al. (32)]. All of these patients underwent an MRI examination using a standardized protocol including ASL PWI. Of the 76 patients, six were excluded due to suboptimal MRI quality (motion artifacts) and a further five patients due to poor cerebellar coverage. The study population was formed by the remaining 65 $(85.5 \%)$ patients and retrospectively studied with regard to demographic details, clinical aspects, and MRI findings. All patients were tested with the Mini-Mental State Examination as part of their initial clinical assessment. The study was approved by the local Institutional Review Board (Medizinische EthikKommission II der Medizinischen Fakultät Mannheim). Because of the retrospective nature of this study and the lack of interaction with patients, informed consent was not required. This study was performed in accordance with the ethical standards laid down in the 1964 Declaration of Helsinki and its later amendments.

MRI studies. Magnetic resonance imaging was performed on a 3.0T MR system (Magnetom Trio, Siemens Medical Systems, Erlangen, Germany) with a 32-channel head coil (Siemens Healthcare). A standardized protocol was used for all patients including (i) transverse, coronal and sagittal localizing sequences followed by transverse oblique contiguous images aligned with the inferior borders of the corpus callosum (applied on sequences ii to v); (ii) T2-weighted images; (iii) fluid attenuated inversion recovery images; (iv) diffusion weighted images; (v) susceptibility-weighted images; (vi) pulsed ASL PWI (field of view $256 \times 256$, acquisition matrix $64 \times 64$, number of sclices 9 , slice thickness $8 \mathrm{~mm}$, echo time $11 \mathrm{~ms}$, repetition time $2500 \mathrm{~ms}$, number of averages: 1, duration 5:57 $\mathrm{min}$ ); and (7) magnetization-prepared rapid gradient-echo.

MRI postprocessing. The pulsed ASL images were motion-corrected and the relative CBF values calculated inline on the MRI scanner by the routine provided by the manufacturer (3D Prospective Acquisition Correction).

Brain volumetric measurements were carried out with a new commercially available AI-powered software solution mdbrain (mediaire GmbH, Berlin, Germany; https://mediaire.de/). Brain
Table I. Demographic characteristics and volumetric findings in patients with Alzheimer's disease.

$\mathrm{n}=65$

\begin{tabular}{llc}
\hline Demographic & & \\
Age, years & Median (IQR) & $74(51-88)$ \\
Gender, $\mathrm{n}(\%)$ & Male & $37(56.9)$ \\
Mean volume \pm SD, $\mathrm{ml}$ & Whole brain & $883.2 \pm 60.1$ \\
& Grey matter & $516.2 \pm 45.3$ \\
& White matter & $367.1 \pm 31.3$ \\
& Right frontal lobe & $51.5 \pm 5.2$ \\
& Right parietal lobe & $70.7 \pm 7.4$ \\
& Right temporal lobe & $39.5 \pm 4.6$ \\
& Right occipital lobe & $27.1 \pm 3.8$ \\
& Right hippocampus & $2.6 \pm 0.4$ \\
& Right amygdala & $1.3 \pm 0.3$ \\
& Right thalamus & $6.7 \pm 1.0$ \\
& Left frontal lobe & $48.2 \pm 5.5$ \\
& Left parietal lobe & $68.4 \pm 7.5$ \\
& Left temporal lobe & $40.3 \pm 4.1$ \\
& Left occipital lobe & $29.7 \pm 3.3$ \\
& Left hippocampus & $2.7 \pm 0.5$ \\
& Left amygdala & $1.2 \pm 0.3$ \\
& Left thalamus & $6.5 \pm 0.8$ \\
\hline
\end{tabular}

IQR: Interquartile range; SD: standard deviation.

volumetry was performed for: Whole brain, grey and white matter, frontal, parietal, occipital, temporal lobe, hippocampus and all ventricles.

Segmentation of further subcortical structures (amygdala, thalamus) was performed by use of FIRST, a model-based segmentation tool in the Oxford Centre for Functional Magnetic Resonance Imaging of the Brain (FMRIB) Software Library (FSL) (www.fmrib.ox.ac.uk/fsl) (33). Following this, the volume of these subcortical structures was calculated by using FSL Stats.

Image analysis. All MRI scans were reviewed by two readers (A.F., with more than 10 years of experience in neuroimaging, and A.H. with 2 years of experience in neuroimaging) blinded to the clinical information. Cases with discrepancies were rereviewed by both readers and discussed until a consensus was reached. CCD and ITD were assessed both qualitatively and quantitatively. Qualitatively, CCD and ITD were defined as a unilateral signal decrease in the cerebellum or thalamus, respectively, on the CBF maps of ASL imaging, and categorized as absent or present as established recently (21). Quantitatively, the signal intensity of both cerebellar hemispheres and thalami was measured in the CBF map of ASL imaging by manually placed circular regions of interest and mirroring them on the other hemisphere using OsiriX multidimensional image navigation and display software (34). The regions of interest used for assessing the signal intensity of the cerebellum had the size of $7.2 \mathrm{~cm}^{2}$, and that used for assessing the signal intensity of the thalami was 1.4 $\mathrm{cm}^{2}$. The results were used to calculate an asymmetry index (AI) between the affected (A) and unaffected (U) cerebellar hemisphere as follows:

$\mathrm{AI}=(\mathrm{U}-\mathrm{A}) / \mathrm{U} \times 100 \%$ 
Table II. Comparison of volumetric findings in crossed cerebellar diaschisis (CCD)-positive and -negative patients with Alzheimer's disease.

\begin{tabular}{lccc}
\hline & \multicolumn{2}{c}{ Mean volume \pm SD, ml } & \\
\cline { 2 - 3 } Structure & $\mathrm{CCD}, \mathrm{n}=22$ & No CCD, $\mathrm{n}=45$ & \\
\hline Whole brain & $862.8 \pm 49.9$ & $893.7 \pm 62.7$ & $\mathbf{0 . 0 4 9}$ \\
Grey matter & $509.9 \pm 30.1$ & $519.4 \pm 51.4$ & 0.43 \\
White matter & $352.9 \pm 28.0$ & $374.3 \pm 30.7$ & $\mathbf{0 . 0 0 8}$ \\
Right frontal lobe & $69.8 \pm 5.2$ & $71.2 \pm 8.3$ & 0.49 \\
Right parietal lobe & $39.1 \pm 4.2$ & $39.7 \pm 4.8$ & 0.65 \\
Right temporal lobe & $51.6 \pm 4.1$ & $51.4 \pm 5.8$ & 0.86 \\
Right occipital lobe & $26.7 \pm 3.3$ & $27.3 \pm 4.0$ & 0.57 \\
Right hippocampus & $2.6 \pm 0.4$ & $2.6 \pm 0.5$ & 0.59 \\
Right amygdala & $1.2 \pm 0.3$ & $1.3 \pm 0.3$ & 0.20 \\
Right thalamus & $6.5 \pm 0.9$ & $6.5 \pm 0.8$ & 0.99 \\
Left frontal lobe & $67.5 \pm 6.1$ & $69.0 \pm 8.1$ & 0.46 \\
Left parietal lobe & $40.1 \pm 4.1$ & $40.3 \pm 4.2$ & 0.81 \\
Left temporal lobe & $47.5 \pm 4.9$ & $48.5 \pm 5.9$ & 0.51 \\
Left occipital lobe & $29.3 \pm 3.0$ & $29.9 \pm 3.4$ & 0.51 \\
Left hippocampus & $2.6 \pm 0.4$ & $2.7 \pm 0.5$ & 0.47 \\
Left amygdala & $1.3 \pm 0.3$ & $1.4 \pm 0.2$ & 0.12 \\
Left thalamus & $6.7 \pm 1.1$ & $6.7 \pm 0.9$ & 0.83 \\
\hline
\end{tabular}

SD: Standard deviation. Statistically significant $p$-values are shown in bold.

An AI of $\geq 20 \%$ was considered positive for CCD/ITD. A competing cerebellar pathology was excluded on diffusion-weighted images, T1- and T2-weighted as well as fluid-attenuated inversion recovery images.

Statistical analysis. All statistical analyses were carried out using Statistical Product and Service Solutions (SPSS) statistics for Windows Version 24.0 (IBM Corp., Armonk, NY, USA). The analysis of descriptive data and comparison of the different anatomical brain region volumes in patients with and without $\mathrm{CCD}$ or ITD, respectively, was performed by use of Student's $t$-test. A $p$ value less than 0.05 was considered significant.

\section{Results}

Demographics. Overall, 65 out of $76(85.5 \%)$ patients were included in the final analysis. The mean age was $74.1 \pm 10.3$ years; 37 (56.9\%) patients were male, and $28(43.1 \%)$ female. The median Mini-Mental State Examination score was 21 [interquartile range $(\mathrm{IQR})=19-24$ ].

MRI and ASL perfusion analysis. Qualitatively 27 (41.5\%) patients were assessed as CCD-positive and 15 (23.1\%) patients as ITD-positive. Quantitatively 22 (33.8\%) patients were assessed as CCD-positive and 11 (16.9\%) as ITDpositive. Additionally, in two (3.1\%) patients, a more extensive area of hypoperfusion involving the left hemisphere was observed. Patients with CCD had a significant lower
Table III. Comparison of volumetric findings in ipilateral thalamic diaschisis (ITD)-positive and -negative patients with Alzheimer's disease.

\begin{tabular}{lccc}
\hline & \multicolumn{2}{c}{ Mean volume \pm SD, $\mathrm{ml}$} & \\
\cline { 2 - 3 } Structure & ITD, $\mathrm{n}=11$ & No ITD, $\mathrm{n}=54$ & \\
\cline { 2 - 3 } & & & \\
\hline Whole brain & $884.8 \pm 43.7$ & $882.9 \pm 63.2$ & 0.93 \\
Grey matter & $513.1 \pm 26.4$ & $516.8 \pm 48.4$ & 0.81 \\
White matter & $371.7 \pm 28.1$ & $366.1 \pm 32.1$ & 0.59 \\
Right frontal lobe & $71.0 \pm 4.4$ & $70.6 \pm 7.9$ & 0.89 \\
Right parietal lobe & $39.9 \pm 3.7$ & $39.4 \pm 4.8$ & 0.75 \\
Right temporal lobe & $51.1 \pm 3.5$ & $51.5 \pm 5.5$ & 0.79 \\
Right occipital lobe & $26.9 \pm 2.9$ & $27.2 \pm 4.0$ & 0.82 \\
Right hippocampus & $2.6 \pm 0.4$ & $2.6 \pm 0.4$ & 0.28 \\
Right amygdala & $1.2 \pm 0.2$ & $1.3 \pm 0.3$ & 0.33 \\
Right thalamus & $6.4 \pm 0.8$ & $6.5 \pm 0.8$ & 0.85 \\
Left frontal lobe & $68.1 \pm 5.6$ & $68.6 \pm 7.8$ & 0.85 \\
Left parietal lobe & $40.7 \pm 3.1$ & $40.2 \pm 4.3$ & 0.72 \\
Left temporal lobe & $47.2 \pm 3.9$ & $48.4 \pm 5.8$ & 0.55 \\
Left occipital lobe & $29.7 \pm 2.0$ & $29.6 \pm 3.5$ & 0.93 \\
Left hippocampus & $2.6 \pm 0.4$ & $2.7 \pm 0.5$ & 0.29 \\
Left amygdala & $1.3 \pm 0.2$ & $1.4 \pm 0.3$ & 0.23 \\
Left thalamus & $6.5 \pm 1.0$ & $6.7 \pm 0.9$ & 0.56 \\
\hline
\end{tabular}

ITD: Ipsilateral thalamic diaschisis; SD: standard deviation.

relative $\mathrm{CBF}$ (mean $\mathrm{AI}=29.0 \pm 14.1$ ) in the respective cerebellar hemisphere compared to patients without $\mathrm{CCD}$ (mean $\mathrm{AI}=9.6 \pm 6.1, p<0.001)$. Similarly, patients with ITD had a significantly lower relative $\mathrm{CBF}$ (mean $\mathrm{AI}=22.3 \pm 1.5$ ) in the respective thalamus in comparison to patients without ITD (mean $\mathrm{AI}=8.7 \pm 5.4, p<0.001$ ).

The mean volume of the hippocampus was $3.1 \pm 0.6 \mathrm{ml}$, of the amygdala $1.3 \pm 0.3 \mathrm{ml}$ and of the thalamus $6.5 \pm 0.8 \mathrm{ml}$. The mean total volume of the cerebrum was $883.2 \pm 60.1 \mathrm{ml}$. For details on grey and white matter volume as well as frontal, parietal, temporal, and occipital lobe volumes see Table I. Patients with CCD had a significantly smaller whole brain volume $(862.8 \pm 49.9 v s .893 .7 \pm 62.7 \mathrm{ml}, p=0.049)$ as well as white matter volume $(352.9 \pm 28.0 \mathrm{vs}$. $374.3 \pm 30.7$, $p=0.008$ ) in comparison to patients without CCD. Comparing the determined volumes of the hippocampus, amygdala, or thalamus as well as whole brain, grey and white matter, frontal, parietal, temporal, and occipital lobe in patients with and without CCD or ITD, no further differences were found. For details see Tables II and III. Regarding the median Mini-Mental State Examination scores, no significant differences between patients with and without CCD [21 (IQR=15.75-24) vs. 22 (IQR=20-25), respectively, $p=0.3]$, or ITD [19 (IQR=14-24) vs. 22 (IQR=20-24.5), respectively, $p=0.1]$ were found.

In two patients with $\mathrm{CCD}$, a marked decrease of relative $\mathrm{CBF}$ in the ipsilateral thalamus matching ITD was observed 


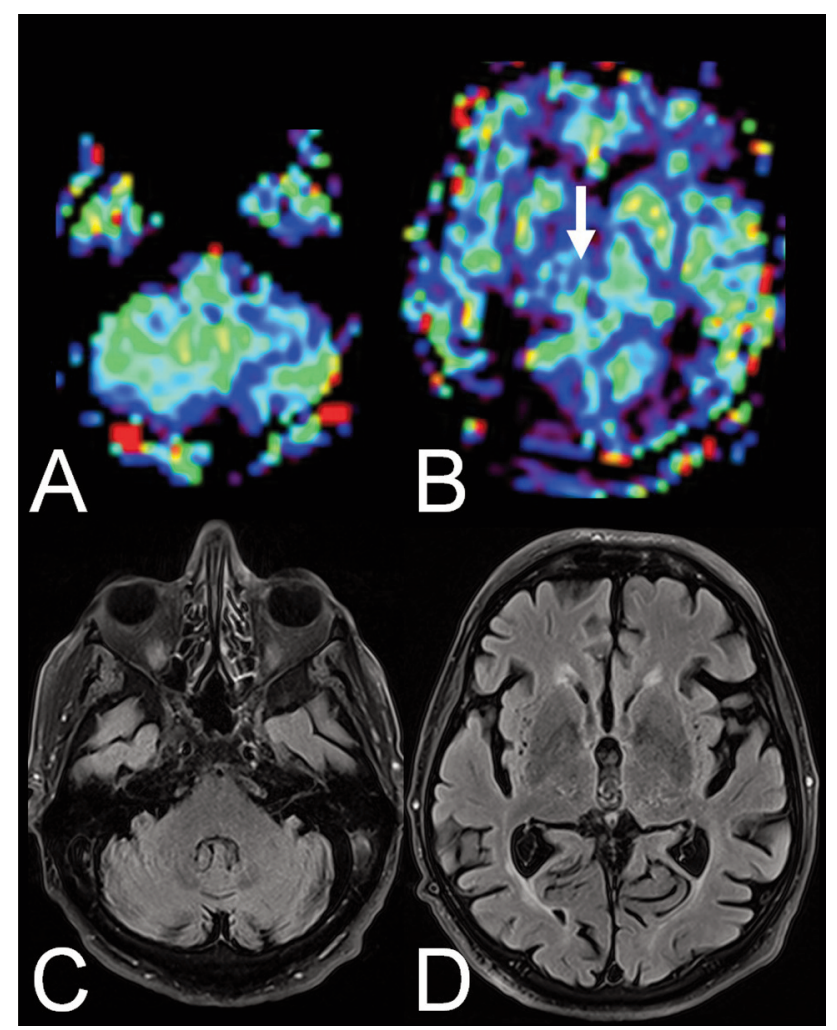

Figure 1. Example of a crossed cerebellar diaschisis and ipsilateral thalamic diaschisis-positive patient with Alzheimer's disease. Arterial spin labeling perfusion magnetic resonance images showed reduced relative cerebral blood flow in the left cerebellum (A) and the right thalamus ( $B$, arrow). On fluid-attenuated inversion recovery images, the cerebellum $(C)$ and the thalami $(D)$ were unremarkable.

(for an example see Figure 1). In a further two patients with $\mathrm{CCD}$, a marked decrease of $\mathrm{rCBF}$ in the ipsilateral hemisphere was observed (for an example see Figure 2).

\section{Discussion}

The term 'diaschisis' describing a potentially reversible depression of regional neuronal metabolism and cerebral blood flow caused by dysfunction in an anatomically separated but functionally related neuronal region was introduced as a possible explanation for clinical signs and symptoms without an obvious apparent morphological cerebral lesion $(1,4)$. Baron et al. first described CCD following a supratentorial lesion by detecting a depressed metabolism in the cerebellar hemisphere contralateral to the infarction in a positron-emission tomography (7).

While CCD has been well evaluated in patients with ischemic stroke or hemorrhage, only a few reports have been published regarding the presence of CCD in patients with Alzheimer's disease $(14,15)$. In 1989, Akiyama and

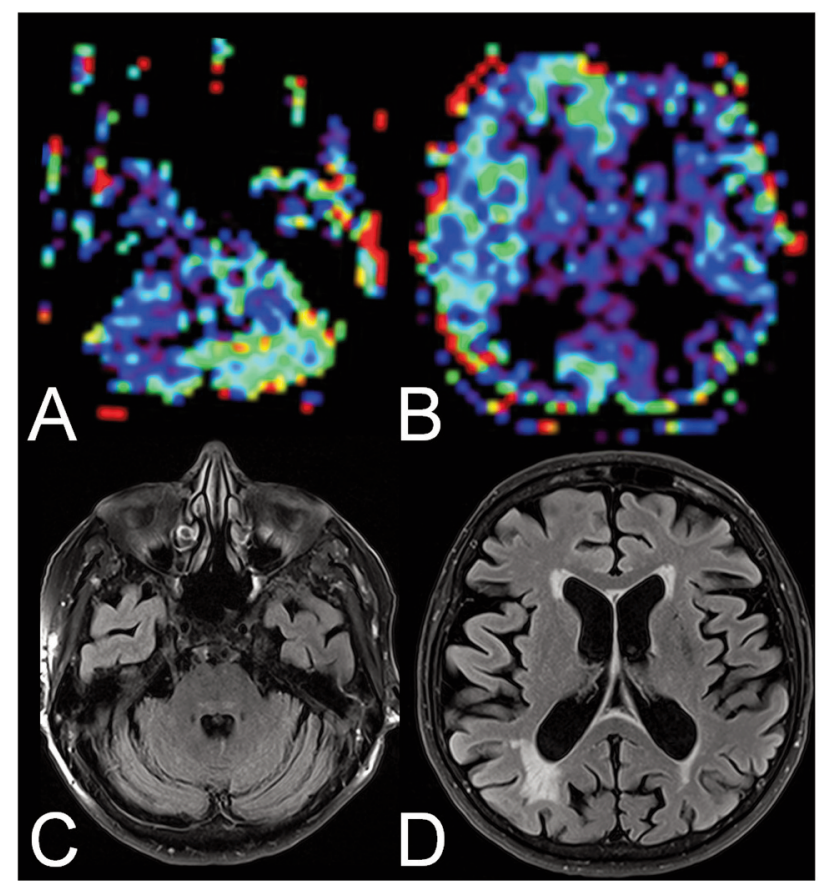

Figure 2. Example of a crossed cerebellar diaschisis-positive patient with Alzheimer's disease with extensive reduced relative cerebral blood flow in the ipsilateral hemisphere. Arterial spin labeling perfusion magnetic resonance images showed reduced relative cerebral blood flow in the right cerebellum $(A)$ and the left cerebral hemisphere $(B)$. On fluid-attenuated inversion recovery images the cerebellum $(C)$ and the left cerebral hemisphere $(D)$ were unremarkable. colleagues performed PET scans in 26 patients with Alzheimer's disease. Of these, seven (27\%) demonstrated significant CCD, and four (15\%) showed ITD (14). The frequency found in the present study is comparable as we demonstrated CCD in $33.8 \%$, and ITD in $16.9 \%$ of patients. Furthermore, the results of our study are in line with other studies evaluating CCD in other neurological disorders and diseases by the use of ASL perfusion imaging $(22,23)$. Thus, ASL perfusion MRI seems to be feasible for detection of alterations in regional perfusion consistent with CCD or ITD in patients with Alzheimer's disease and may be used in future studies focusing upon these phenomena. ASL perfusion imaging offers several advantages, such as lower costs and greater availability in particular, as it may be easily added to a standard routine MRI protocol. Due to the lack of an exogenous contrast agent, ASL might also be used for multiple follow-up measurements in longitudinal studies (27).

Patients with Alzheimer's disease with CCD had a significantly smaller whole brain volume as well as white matter volume compared to patients without CCD. Several 
studies demonstrated that white matter abnormalities and loss might reflect secondary degenerative processes in more advanced stages of Alzheimer's disease (35). However, while patients with Alzheimer's disease with CCD demonstrated a significantly smaller whole brain and white matter volumes, no more pronounced clinical severity as assessed by the Mini-Mental State Examination was observed in patients with Alzheimer's disease with CCD compared to those without CCD. Thus, these findings might indicate that the development of CCD is rather more dependent on the interruption of specific critical pathways such as corticoponto-cerebellar fibres or the dentato-rubrothalamic pathway, which are believed to cause the development of $\operatorname{CCD}(9,36)$ than the extent of brain atrophy, and in particular especially on white matter volume in general.

To the contrary, no significant correlation between the occurrence of CCD or ITD and the volume of a more specific anatomical region (such as hippocampus, amgydala, thalamus, frontal, parietal, temporal or occipital lobe) was found whether ipsilateral or contralateral. Similarly, Luckhaus and colleagues investigated the association between reduced relative blood flow in certain brain areas and the volume of hippocampi and amygdalae in patients with mild cognitive impairment and early-stage Alzheimer's disease and found no significant correlations.

Besides the atrophy of critical pathways in the clinical course, reduced functional activity and consequently reduced relative $\mathrm{CBF}$ in different brain areas might contribute to the development of $\mathrm{CCD}$, as indicated by the four cases with $\mathrm{CCD}$ with associated hypoperfusion in the ipsilateral thalamus or the ipsilateral hemisphere consistent with functional impairment or disconnection. Previous studies were not only able to demonstrate a decrease of $\mathrm{rCBF}$ in frontal, temporal, parietal, and occipital regions in more advanced stages of Alzheimer's disease $(37,38)$ but also a left lateralization of regional CBF decrease $(15,38)$. Similarly, other studies also demonstrated a left lateralization of reduced glucose metabolism (39), and grey matter atrophy (40). This finding might possibly be associated with faster progression of disease (41).

The present study has some limitations. Firstly, this was a retrospective case series of moderate size. Secondly, only a subset of patients with CCD underwent follow-up MRI including ASL PWI. Thus, we cannot draw any conclusions about the evolution of the observed perfusion abnormalities with time. Thirdly, compared to PET perfusion, MRI techniques have a lower sensitivity in depicting subtle hemodynamic alterations and, as a consequence, some cases of CCD might have been missed. Finally, another important limitation of ASL PWI is its restricted spatial resolution and susceptibility to bone artifacts, especially in the posterior fossa.

In conclusion, in the present study ASL PWI had a detection rate for CCD of approximately $30 \%$ and a detection rate for ITD of nearly $17 \%$ in patients with
Alzheimer's disease. Presence of CCD was associated with smaller whole brain and white matter volumes and might indicate a more pronounced stage of disease. Since ASL PWI provides a sufficient sensitivity and has further advantages, such as its broad availability, low costs and the absence of an exogenous contrast agent, it seems to be a useful alternative method for the detection and further studying of CCD as well as other forms of diaschisis such as ITD in patients with Alzheimer's disease.

\section{Conflicts of Interest}

None of the Authors had any conflicts of interest in regard to this study.

\section{Authors' Contributions}

Alexander Hertel: analysis and interpretation of the data, drafting and revising the article. Holger Wenz, Mansour Al-Zghloul and Lucrezia Hausner: acquisition of the data and revising the article. Lutz Frölich and Christoph Groden: interpretation of the data, revising the article. Alex Förster design of the study, analysis of the data and revising the article.

\section{References}

1 von Monakow C: Die Lokalisation im Grosshirn und der Abbau der Funktion durch kortikale Herde. J.F. Bergmann, Wiesbaden, 1914.

2 Feeney DM and Baron JC: Diaschisis. Stroke 17(5): 817-830, 1986. PMID: 3532434. DOI: 10.1161/01.str.17.5.817

3 Andrews RJ: Transhemispheric diaschisis. A review and comment. Stroke 22(7): 943-949, 1991. PMID: 1853416. DOI: 10.1161/01 str.22.7.943

4 Carrera E and Tononi G: Diaschisis: past, present, future. Brain 137(9): 2408-2422, 2014. PMID: 24871646. DOI: 10.1093/ brain/awu101

5 Baron JC, D'Antona R, Pantano P, Serdaru M, Samson Y and Bousser MG: Effects of thalamic stroke on energy metabolism of the cerebral cortex. A positron tomography study in Man. Brain 109(6): 1243-1259, 1986. PMID: 3491655. DOI: 10.1093/brain/109.6.1243

6 Baron JC, Levasseur M, Mazoyer B, Legault-Demare F, Mauguiere F, Pappata S, Jedynak P, Derome P, Cambier J and Tran-Dinh S: Thalamocortical diaschisis: positron emission tomography in humans. J Neurol Neurosurg Psychiatry 55(10): 935-942, 1992. PMID: 1431957. DOI: 10.1136/jnnp.55.10.935

7 Baron JC, Bousser MG, Comar D and Castaigne P: "Crossed cerebellar diaschisis" in human supratentorial brain infarction. Trans Am Neurol Assoc 105: 459-461, 1981. PMID: 19645126.

8 Pantano P, Baron JC, Samson Y, Bousser MG, Derouesne C and Comar D: Crossed cerebellar diaschisis. Further studies. Brain 109(4): 677-694, 1986. PMID: 3488093. DOI: 10.1093/ brain/109.4.677

9 Tanaka M, Kondo S, Hirai S, Ishiguro K, Ishihara $\mathrm{T}$ and Morimatsu M: Crossed cerebellar diaschisis accompanied by hemiataxia: A PET study. J Neurol Neurosurg Psychiatry 55(2): 121-125, 1992. PMID: 1538216. DOI: 10.1136/jnnp.55.2.121 
10 Lim JS, Ryu YH, Kim BM and Lee JD: Crossed cerebellar diaschisis due to intracranial hematoma in basal ganglia or thalamus. J Nucl Med 39(12): 2044-2047, 1998. PMID: 9867139.

11 Engelborghs S, Pickut BA, Marien P, Opsomer F and De Deyn PP: Crossed cerebellar diaschisis and hemiataxia after thalamic hemorrhage. J Neurol 247(6): 476-477, 2000. PMID: 10929283. DOI: $10.1007 / \mathrm{s} 004150070183$

12 de Silva R, Duncan R, Patterson J, Gillham R and Hadley D: Regional cerebral perfusion and amytal distribution during the Wada test. J Nucl Med 40(5): 747-752, 1999. PMID: 10319745.

13 Kellner-Weldon F, El Koussy M, Jung S, Jossen M, KlingerGratz and Wiest R: Cerebellar hypoperfusion in migraine attack: Incidence and significance. AJNR Am J Neuroradiol 39(3): 435440, 2018. PMID: 29326138. DOI: 10.3174/ajnr.A5508

14 Akiyama H, Harrop R, McGeer PL, Peppard R and McGeer EG: Crossed cerebellar and uncrossed basal ganglia and thalamic diaschisis in Alzheimer's disease. Neurology 39(4): 541-548, 1989. PMID: 2784550. DOI: $10.1212 /$ wn1.39.4.541

15 Reesink FE, Garcia DV, Sanchez-Catasus CA, Peretti DE, Willemsen AT, Boellaard R, Meles SK, Huitema RB, de Jong BM, Dierckx RA and De Deyn PP: Crossed cerebellar diaschisis in Alzheimer's disease. Curr Alzheimer Res 15(13): 1267-1275, 2018. PMID: 30210001. DOI: 0.2174/1567205015666180913102615

16 Wenk GL: Neuropathologic changes in Alzheimer's disease. J Clin Psychiatry 64 Suppl 9: 7-10, 2003. PMID: 12934968.

17 McGeer PL, Kamo H, Harrop R, Li DK, Tuokko H, McGeer EG, Adam MJ, Ammann W, Beattie BL and Calne DB: Positron emission tomography in patients with clinically diagnosed Alzheimer's disease. CMAJ 134(6): 597-607, 1986. PMID: 3512063.

18 Nguyen DK and Botez MI: Diaschisis and neurobehavior. Can J Neurol Sci 25(1): 5-12, 1998. PMID: 9532275. DOI: $10.1017 / \mathrm{s} 0317167100033424$

19 Lin DD, Kleinman JT, Wityk RJ, Gottesman RF, Hillis AE, Lee AW and Barker PB: Crossed cerebellar diaschisis in acute stroke detected by dynamic susceptibility contrast MR perfusion imaging. Am J Neuroradiol 30(4): 710-715, 2009. PMID: 19193758. DOI: 10.3174/ajnr.A1435

20 Förster A, Kerl HU, Goerlitz J, Wenz H and Groden C: Crossed cerebellar diaschisis in acute isolated thalamic infarction detected by dynamic susceptibility contrast perfusion MRI. PLoS One 9(2): e88044, 2014. PMID: 24505372. DOI: 10.1371/journal.pone. 0088044

21 Kang KM, Sohn CH, Choi SH, Jung KH, Yoo RE, Yun TJ, Kim JH and Park SW: Detection of crossed cerebellar diaschisis in hyperacute ischemic stroke using arterial spin-labeled MR imaging. PLoS One 12(3): e0173971, 2017. PMID: 28323841. DOI: 10.1371/journal.pone.0173971

22 Chen S, Guan M, Lian HJ, Ma LJ, Shang JK, He S, Ma MM, Zhang ML, Li ZY, Wang MY, Shi DP and Zhang JW: Crossed cerebellar diaschisis detected by arterial spin-labeled perfusion magnetic resonance imaging in subacute ischemic stroke. J Stroke Cerebrovasc Dis 23(9): 2378-2383, 2014. PMID: 25183560. DOI: 10.1016/j.jstrokecerebrovasdis.2014.05.009

23 Strother MK, Buckingham C, Faraco CC, Arteaga DF, Lu P, Xu $\mathrm{Y}$ and Donahue MJ: Crossed cerebellar diaschisis after stroke identified noninvasively with cerebral blood flow-weighted arterial spin labeling MRI. Eur J Radiol 85(1): 136-142, 2016. PMID: 26724658. DOI: 10.1016/j.ejrad.2015.11.003
24 Lin T, Lyu Y, Qu J, Cheng X, Fan X, Zhang Y, Hou B, You $\mathrm{H}$, Ma W and Feng F: Crossed cerebellar diaschisis in posttreatment glioma patients: A comparative study of arterial spin labelling and dynamic susceptibility contrast. Eur J Radiol 107: 70-75, 2018. PMID: 30292276. DOI: 10.1016/j.ejrad.2018.08.001

25 Won J, Choi DS, Hong SJ, Shin HS, Baek HJ, Choi HC, Kim M and Kim RB: Crossed cerebellar hyperperfusion in patients with seizure-related cerebral cortical lesions: an evaluation with arterial spin labelling perfusion MR imaging. Radiol Med 123(11): 843-850, 2018. PMID: 30292276. DOI: 10.1016 /j.ejrad.2018.08.001

26 Schertz J, Benzakoun M, Pyatigorskaya N, Belkacem S, SahliAmor M, Navarro V, Cholet C, Leclercq D, Dormont D and Law-Ye B: Specificities of arterial spin labeling (ASL) abnormalities in acute seizure. J Neuroradiol 47(1): 20-26, 2020. PMID: 30500358. DOI: 10.1016/j.neurad.2018.11.003

27 Petcharunpaisan S, Ramalho J and Castillo M: Arterial spin labeling in neuroimaging. World J Radiol 2(10): 384-398, 2010. PMID: 21161024. DOI: 10.4329/wjr.v2.i10.384

28 Wintermark M, Sesay M, Barbier E, Borbely K, Dillon WP, Eastwood JD, Glenn TC, Grandin CB, Pedraza S, Soustiel JF, Nariai T, Zaharchuk G, Caille JM, Dousset V and Yonas H: Comparative overview of brain perfusion imaging techniques. J Neuroradiol 32(5): 294-314, 2005. PMID: 16424829. DOI: 10.1016/s0150-9861(05)83159-1

29 Liu TT and Brown GG: Measurement of cerebral perfusion with arterial spin labeling: Part 1. Methods. J Int Neuropsychol Soc 13(3): 517-525, 2007. PMID: 17445301. DOI: 10.1017/S13 55617707070646

30 Detre JA, Leigh JS, Williams DS and Koretsky AP: Perfusion imaging. Magn Reson Med 23(1): 37-45, 1992. PMID: 1734182. DOI: $10.1002 / \mathrm{mrm} .1910230106$

31 Brown GG, Clark C and Liu TT: Measurement of cerebral perfusion with arterial spin labeling: Part 2. Applications. J Int Neuropsychol Soc 13(3): 526-538, 2007. PMID: 17445301. DOI: $10.1017 / \mathrm{S} 1355617707070646$

32 McKhann G, Drachman D, Folstein M, Katzman R, Price D and Stadlan EM: Clinical diagnosis of Alzheimer's disease: report of the NINCDS-ADRDA Work Group under the auspices of Department of Health and Human Services Task Force on Alzheimer's Disease. Neurology 34(7): 939-944, 1984. PMID: 6610841. DOI: 10.1212/wnl.34.7.93

33 Patenaude B, Smith SM, Kennedy DN and Jenkinson M: A Bayesian model of shape and appearance for subcortical brain segmentation. Neuroimage 56(3): 907-922, 2011. PMID: 21352927. DOI: 10.1016/j.neuroimage.2011.02.046

34 Rosset A, Spadola L and Ratib O: OsiriX: an open-source software for navigating in multidimensional DICOM images. J Digit Imaging 17(3): 205-216, 2004. PMID: 15534753. DOI: 10.1007/s10278-004-1014-6

35 Agosta F, Pievani M, Sala S, Geroldi C, Galluzzi S, Frisoni GB and Filippi M: White matter damage in Alzheimer disease and its relationship to gray matter atrophy. Radiology 258(3): 853863, 2011. PMID: 21177393. DOI: 10.1148/radiol.10101284

36 Gold L and Lauritzen M: Neuronal deactivation explains decreased cerebellar blood flow in response to focal cerebral ischemia or suppressed neocortical function. Proc Natl Acad Sci USA 99(11): 7699-7704, 2002. PMID: 12032346. DOI: $10.1073 /$ pnas. 112012499 
37 Frölich L, Eilles C, Ihl R, Maurer K and Lanczik M: Stagedependent reductions of regional cerebral blood flow measured by HMPAO-SPECT in dementia of Alzheimer type. Psychiatry Res 29(3): 347-350, 1989. PMID: 2608792. DOI: 10.1016/01651781(89)90085-1

38 Thome J, Frölich L, Scheubeck M, Hissnauer G, Becker T, Foley P, Wiesbeck G, Vince G, Maurer K and Rosier M: Left hemispheric reductions of regional cerebral blood flow ( $\mathrm{rCBF}$ ) correlate with measures of dementia severity in patients with Alzheimer's disease: A SPECT study. Eur Psychiatry 11(6): 314318, 1996. PMID: 19698472. DOI: 10.1016/S0924-9338(96) 89900-7

39 Loewenstein DA, Barker WW, Chang JY, Apicella A, Yoshii F, Kothari P, Levin B and Duara R: Predominant left hemisphere metabolic dysfunction in dementia. Arch Neurol 46(2): 146-152, 1989. PMID: 2783845. DOI: 10.1001/archneur.1989.0052038 0046012
40 Thompson PM, Hayashi KM, de Zubicaray G, Janke AL, Rose SE, Semple J, Herman D, Hong MS, Dittmer SS, Doddrell DM and Toga AW: Dynamics of gray matter loss in Alzheimer's disease. J Neurosci 23(3): 994-1005, 2003. PMID: 12574429. DOI: 10.1523/JNEUROSCI.23-03-00994.2003

41 Wachinger C, Salat DH, Weiner M and Reuter M: Whole-brain analysis reveals increased neuroanatomical asymmetries in dementia for hippocampus and amygdala. Brain 139(Pt 12): 3253 3266, 2016. PMID: 27913407. DOI: 10.1093/brain/aww243

Received December 5, 2020

Revised December 27, 2020

Accepted January 5, 2021 